\title{
Population Ageing and Socially Assistive Robots for Elderly Persons: The Importance of Sociodemographic Factors for User Acceptance
}

\author{
Priska Flandorfer \\ Wittgenstein Centre for Demography and Global Human Capital, Vienna Institute of Demography, Austrian Academy of Sciences, \\ Wohllebengasse 12-14, 1040 Vienna, Austria \\ Correspondence should be addressed to Priska Flandorfer, priska.flandorfer@oeaw.ac.at
}

Received 2 November 2011; Revised 30 January 2012; Accepted 6 February 2012

Academic Editor: Shirlena Huang

Copyright () 2012 Priska Flandorfer. This is an open access article distributed under the Creative Commons Attribution License, which permits unrestricted use, distribution, and reproduction in any medium, provided the original work is properly cited.

Taking care of older adults is among the major challenges currently faced by ageing populations. Researchers, designers, and engineers have proposed socially assistive robots as one way of helping elderly people stay in their homes longer. In a systematic literature review, this paper wants to investigate if and how evaluations of the acceptance of socially assistive robots by older people take into account sociodemographic factors. The results indicate that this only holds true for a few studies. Research that incorporates age, gender, education, and so forth; clearly shows that these key factors have a significant impact. However, the relations are complex and experience with technology mitigates the influence of sociodemographic factors on acceptance. Assistive devices should be adaptable to individual needs to be able to consider all these factors.

\section{Introduction}

Demographic changes have accelerated population ageing, which, in turn, has an impact on the care of older persons. In view of the increasing demand for care personnel, societies around the world have to find strategies for dealing with these challenges [1]. According to researchers, designers, engineers, and other experts, assistive technologies nowadays permit older persons to live independently in their home longer [2]. Support ranges from telecare/smart homes, proactive service systems, and household robots to robotassisted therapy and socially assistive robots [3]. Surveillance systems can detect when a person falls down, test the blood pressure, recognise severe breathing or heart problems, and immediately warn a caregiver. Interactive robots cooperate with people through bidirectional communication and provide personal assistance with everyday activities such as reminding older persons to take their medication, help them prepare food, eat, and wash [2]. These technological devices collaborate with nursing staff and family members to form a life support network for older persons by offering emotional and physical relief [4].
Japan is deemed to be the first country where population ageing will become relevant in the near future (its old-age dependency ratio is estimated to reach $76 \%$ by 2050). To cope with this situation, the Japanese government wants to introduce a nationwide system of robotic assistive technologies for aged care and heavily invests into the development of so-called service and health-care robots. This is documented by research agendas, roadmaps, and visions of Japanese institutions and ministries. In Europe, investments into assistive devices (financed within the scope of the European Union's Seventh Framework Programme) advance their development. These expenses are justified by an estimated old-age dependency ratio of $49 \%$ by 2050 . Although the situation is less dramatic in the USA (estimated old-age dependency ratio of $34 \%$ by 2050), the US government subsidises the development of robotic assistive technologies, whose innovative potential is reckoned to be comparable to that of the internet and modern media [5]. Advancements in medical care and other fields of society may change the old-age dependency ratio, because older people will stay healthier until higher ages than they do nowadays [6]. As the retirement age increases, older persons might stay more 
independent until higher ages than currently projected on the basis of the old-age dependency ratio.

However, using robots to assist older persons should not be accepted uncritically as a solution to the problems caused by population ageing. In his dissertation, Neven [7] refers to an ageing-and-innovation discourse which revolves around researchers', designers', and engineers' perceptions of older people and presents population ageing as a crisis situation with increasing costs for older persons and decreasing numbers of care staff. Assistive technologies are considered a triple win solution: they not only ease the problems of societies and individual older adults but also propel the economy. Oudshoorn and Pinch state that "different types of users do not necessarily imply homogeneous categories" [8, page 6]. Users may differ in various ways, for example, by gender, age, sociodemographic factors, and culture. Designers, researchers and other professionals involved in devising technologies often fail to critically appraise older adults in line with their individual backgrounds and needs [9]. For example, the script concept based on Akrich [10], which is routed in the Actor Network Theory [11], implies that notions of scripts are used to conceptualise older technology users. Feminist scholars have shown how women are excluded from design [12-14]. They claim that technologies are objects that reflect gender stereotypes. The same holds true for age. Neven found four key user representations. Three of them are homogeneous, generalised representations of older people [7], namely, that older persons are frail, dependent, and ill. These concepts of older adults are hardly ever questioned by designers. In his empirical research, Neven also found that older adults are sometimes pictured as reluctant users or opponents to technological change and as being technologically uninformed. Technological literacy implies that a person understands technical products and is able to interact with them $[15,16]$. These general views of old age are related to social and cultural notions of ageing and stereotype ageist images. As a fourth dimension, Neven found a nuanced exception, namely, the diversity of older individuals. The studies he analysed also comprised some technically very interested persons who were, however, described as exceptions. To avoid that such stereotype user images negatively influence the design process, Neven proposes to assist designers in rethinking their user representations [7].

The purpose of this literature review is to investigate if and how sociodemographic factors of older adults are taken into account in recent empirical studies on socially assistive robots and which influence they have on the acceptance of these devices. The paper does not cover robots solely designed to improve people's psychological well-being. The critical discussion of the findings is based on the ageingand-innovation discourse [7] and the construction of user needs [9]. It wants to contribute to the theoretical debate and to offer suggestions for researchers, designers, and other professionals working in this area on how to consider these important factors.

\section{Socially Assistive Robots for Older Persons}

Assistive robots for older persons can be grouped into rehabilitation robots and socially assistive robots $[17,18]$.
Rehabilitation robots provide physical assistance and are not meant to be social entities. Examples are artificial limbs, exoskeletons, or smart wheelchairs. Socially assistive robots can either be companion-type robots or service-type robots. Often companion-type robots are given the form of a pet and are used to improve the user's health and psychological well-being. The most prominent example is Paro, a Japanese robot in the form of a seal [19-22]. There are also robots that do not fit into any of these categories or combine features of both. This paper does not cover companiontype robots designed to increase the psychological well-being of older persons because they cannot assist them in living independently. The following examples of products under development are not an exhaustive list but give an overview of robots with characteristics that are thought to aid humans.

The iCat is a user interface robot developed by Philips. It can identify sound, speech, and recognise objects and faces through a camera. Moreover, it can be connected to a home network to control domestic appliances or to the internet to obtain information.

BIRON is a mobile robot developed at the University of Bielefeld. It acts as personal assistant. The robot is a modified PeopleBot from ActivMedia. It is equipped with a pan-tilt camera, a pair of microphones, and a laser range finder [23]. It understands speech or hand gestures, identifies objects, and can interact with persons. Users can show the robot objects and places of relevance for later interaction in their private homes. BIRON is thus able to learn from humans by interacting with them. The Cognitive Robot Companion (COGNIRON) can also sense, move, and act. It has cognitive capacities and understands humans and the environment so that it can interact with them. It can fetch and carry objects with its arm.

Wakamaru is a mobile domestic robot developed by Mitsubishi Heavy Industries. It can interact with humans by speaking, shaking hands, and natural conversation. Moreover, it can remind users to take their medication and call for help if there are indications that something might be wrong with them.

These examples give an idea about the types of socially assistive robots that are currently developed and tested. The reviewed research papers offer insights into humanrobot interactions and provide information about how older persons accept these types of robots.

\section{Technology Acceptance versus Robot Acceptance}

Technology has become an important part of our everyday lives. Human-computer studies and human-robot studies focus on the interaction between humans and technological objects. In general, technology acceptance models are used to analyse the complex relationships between different variables and the acceptance of technological products. In studies on robot acceptance, this has some drawbacks because robots are more complex than other technological devices such as computers. Inter alia, their acceptance depends on their shape, functions, and capabilities. They undergo a rapid 
development and can be collaborative, adaptive, and personalised. "Designers should be mindful of users' acceptance, because radical technologies have been shown to not be as readily accepted as incremental innovations. Variables that have been shown to be predictive of acceptance of incremental innovations, may not apply to radical personal robots" [24-26].

The Technology Acceptance Model (TAM) [27] is most prominent concept. It was developed to understand expectations about information technology usage [24] and comprises two main variables that have an impact on acceptance: perceived usefulness and perceived ease of use. Although there is strong empirical support for this model in various technological domains $[28,29]$, its simplicity has been criticised [30]. The TAM does not take sociodemographic factors into account [31]. Another approach is the Unified Theory of Acceptance and Use of Technology (UTAUT) [29], which suggests four key constructs (performance expectancy, effort expectancy, social influence, and facilitating conditions) as direct determinants of usage intention and behaviour. This concept takes into account sociodemographic factors (gender, age) and individual factors (experience, voluntariness of use), which are deemed to be influenced by the four key constructs. For the purpose of this paper, experience with technology, self-efficacy, or felt need is used as examples of (socio)psychological individual factors.

\section{Sociodemographic Factors and Technology Acceptance}

With regard to age, stereotypes suggest that older adults are unwilling, unable, or afraid to use technological appliances. The results of large-scale usage studies highlight the fact that older adults do not use technologies to the same extent as younger persons [32]. However, matters are more complex. Van Dijk [33] discovered that older persons' acceptance level and motivation to use technological devices rise when they discover that the devices are convenient and have useful features. Czaja et al. [34] noted two main barriers for the acceptance of new technologies, namely, low self-efficacy and high anxiety with regard to computer use. Mitzner et al. [32] therefore underline the importance of convincing older persons of the advantages offered by new technologies. Studies have also demonstrated that positive experience with technologies increases people's motivation to use them. Czaja et al. [34] argue that it is important to use a type of technology that allows older persons to experience success. In view of the complexity of assistive robots, this is an important aspect.

Gender is also a factor when it comes to technology acceptance and usage. Men are thought to be more taskoriented [31] and motivated by the need to achieve specific goals. This has a direct impact on their perceived usefulness of a technological gadget. Women's computer self-efficacy is deemed to be lower, which makes it more difficult for them to see the advantages of using such devices [35]. This is a good example for hypotheses that can be analysed by the theory related to the notion of script and/or the construction of user needs $[7,9]$.
Education and/or technological experience also influence access, acceptance, and the use of new technologies [34]. Higher education increases the likelihood of using technological devices. Persons who are familiar with technologies will more readily accept new devices, because they can rely on their past experiences $[31,36]$. However, the influence of these sociodemographic factors is much more complex, because they are interlinked. Older persons might be less educated or less experienced with technological matters and thus may not use technical devices in the same way more educated younger people do [34, 37]. An important point is to bear in mind that the sociodemographic background, education, and experience with technology of future older people will be different. Nowadays people acquire more profound technological knowledge and have learned to use technical devices throughout their lives. Thus the viewpoint of older adults, for example, in 2030, will certainly differ from that of older adults tested now.

How people perceive robots is also subject to psychological factors, which also relate to sociodemographic factors. This will be outlined further in the results section of the paper where detailed facts will be discussed.

\section{Review Methodology}

In April 2011, the PUBMED, ScienceDirect, COCHRANE databases, and the IEEE Digital Library (Xplore) were searched. The search was not limited with regard to the date of publication. The paper only includes papers written in English, that is, scientific papers as well as reports of original research and conference proceedings. Companion-type social robots that mentally stimulate older persons were excluded, unless they were part of a review. There is a wealth of reviews on these types of robots $[2,17,38,39]$; Broadbent's review [2] also includes sociodemographic and individual factors. The focus of this paper is on socially assistive robots that help older adults with their daily activities and as a result support them in living independently.

The articles were subjected to a selection process based on title, abstract, and content as it is depicted in Figure 1. The objective of the search was to find reports on evaluations (e.g., acceptance, perception, attitudes) of socially assistive robots by older persons. Only original research or reviews of available studies were included. The search query was divided into three logical conjunctive components [38]: objective terms (evaluation, etc.), subject (elderly), and means (assistive robots). They were combined with free search terms. To limit the chance of excluding relevant articles, in the first step, the search was solely based on subject and means, that is, the objective was not included. The free words for the subject were "elder*", "old people", and "aged". When using the asterisk $(*)$ the terms become prefixes. The free words for the means were "assis* technol*" and "robot*". In a second step, the identified publications were either searched for "evaluation" or "acceptance" or "attitudes" or "perceptions". In a third step, articles based on the abstracts were selected. The last step was to include all articles that deal with the evaluation of socially assistive robots by older persons. In addition, articles were selected by internet search 


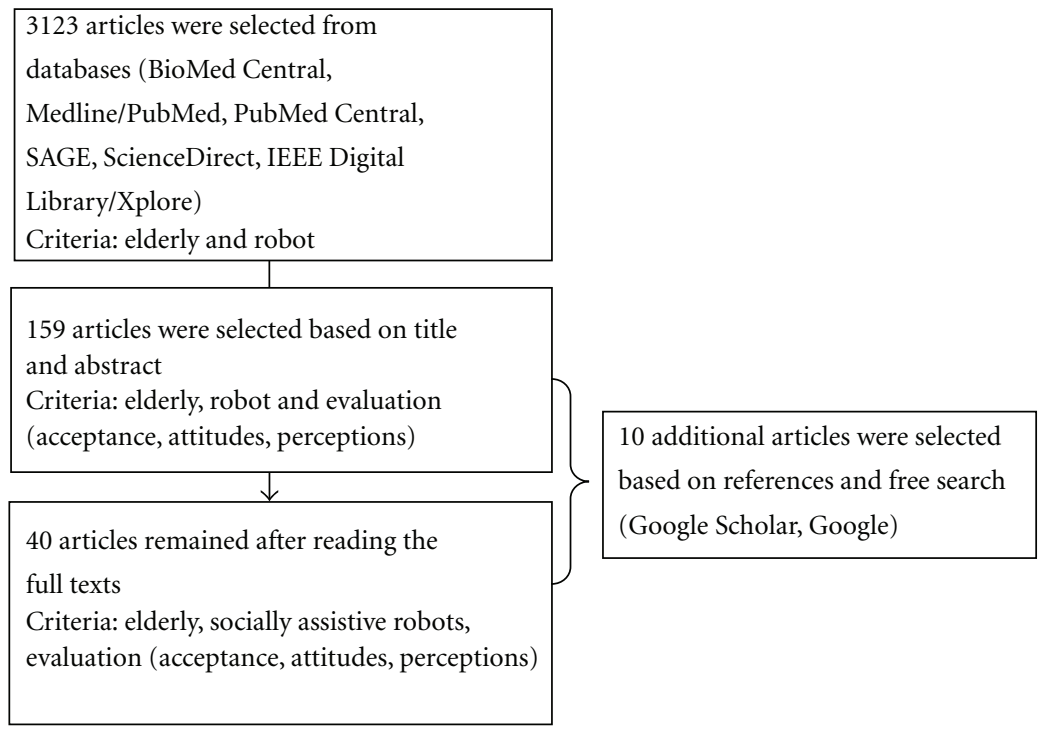

FIGURE 1: Overview of the review process.

(Google, Google Scholar) and based on the reference lists of the selected articles.

\section{Results}

6.1. Sociodemographic Factors in General. 26 out of the 40 studies addressed sociodemographic factors in their empirical research. Table 1 gives an overview of the reviewed studies, the assistive robots or technologies they analysed, the study objective, which sociodemographic variables were explored, and in which country the research was done. Though the studies mention sociodemographic variables such as age, gender, education, cultural background (measured at the national level), family status, income, living conditions, social environment, religious background, profession, and socio-economic status, they tend not to discuss them in detail. Experience with technology is also often mentioned. Although this is not a typical sociodemographic factor, it is included in the paper because it is connected with the other factors. The following section focuses on the five major factors identified in the paper, namely, age, gender, education and technological experience, family status, and cultural background. It describes how these factors influence the acceptance of socially assistive robots by older persons and outlines the strong interrelation between sociodemographic and specific individual factors highlighted by the review.

6.2. Age. Giuliani et al. $[40,41]$ investigated the effect of age on attitudes and behavioural intentions towards technology in general and in everyday situations. Using a gender-specific questionnaire, they asked a sample of 123 persons (62-94 years, balanced with respect to age, gender, and educational level) to evaluate eight scenarios where an old man or woman has problems with his/her daily activities. The results showed that the problem-solving strategy, including the use of technological devices, is related to the specific problem, while personal factors are only relevant in specific situations. They observed that the likelihood of giving up grows with the person's age and that young elderly are more likely to use technological devices. McCreadie and Tinker [42] obtained similar results. They asked a purposive sample of 67 persons $(70+)$ about their use of and experience with various assistive technologies. The results showed a positive reaction by the respondents for straightforward, reliable assistive devices that meet their needs. The newer the device was, the more it was praised. The authors found that chronological age was less important than the older person's felt need; that is, when older persons have specific needs and the device can contribute to fulfilling them, the acceptance is high and the effect of age becomes less important. This shows that predefined hypotheses related to age negatively influence the evaluation, as described by Neven with regard to the construction of user needs [7].

In another study, Scopelliti et al. [43] used a psychological approach to evaluate robots in a domestic setting. The authors started with a qualitative pilot study $(N=23)$ to develop a more structured tool for the quantitative main study. The sample of the quantitative study comprised 120 adults stratified by gender and age groups (young people aged 18-25, adults aged 40-50, elderly people aged 65$75)$. The authors noted that older people worried more about a pleasant integration of robots into the sociophysical environment of their home. However, the results of the quantitative analysis showed no significant differences between age groups and attitudes towards technology, apart from the fact that older people were significantly more suspicious of technology, while younger people were more confident and believed in the potential of technical devices because they were more familiar with them. The older the people were, the more they thought that the devices were far too complicated. Nevertheless they admitted that they made them more independent. When it came to usage patterns, 
TABLE 1: Summary characteristics of included studies.

\begin{tabular}{|c|c|c|c|c|}
\hline Authors & Technology & Objective & $\begin{array}{l}\text { Sociodemographic factors } \\
\text { taken into account }\end{array}$ & Country \\
\hline$[76]$ & iCat & $\begin{array}{l}\text { Study to test if user group appreciates social behaviour of } \\
\text { iCat and its persuasion skills }\end{array}$ & None & The Netherlands \\
\hline$[2]$ & $\begin{array}{l}\text { Health care } \\
\text { robots }\end{array}$ & $\begin{array}{l}\text { Review of the literature on human responses to healthcare } \\
\text { robots }\end{array}$ & $\begin{array}{l}\text { Age, gender, technological } \\
\text { experience, education, } \\
\text { culture }\end{array}$ & $\begin{array}{l}\text { Not } \\
\text { country-specific }\end{array}$ \\
\hline$[38]$ & $\begin{array}{l}\text { Paro, NeCoRo, } \\
\text { Bandit, Aibo }\end{array}$ & Review of the potential of socially assistive robots & Gender, culture & $\begin{array}{l}\text { Not } \\
\text { country-specific }\end{array}$ \\
\hline$[32]$ & $\begin{array}{l}\text { Healthcare } \\
\text { robots }\end{array}$ & $\begin{array}{l}\text { Study about older persons who discussed their use of and } \\
\text { attitudes towards technology in the context of their home, at } \\
\text { work, and in health care }\end{array}$ & Age & $\begin{array}{l}\text { Not } \\
\text { country-specific }\end{array}$ \\
\hline$[42]$ & Assistive robots & $\begin{array}{l}\text { Study to analyse how assistive technology can be acceptable } \\
\text { for the user }\end{array}$ & Age & $\begin{array}{l}\text { United } \\
\text { Kingdom }\end{array}$ \\
\hline$[65]$ & $\begin{array}{l}\text { Telecare and } \\
\text { robots in } \\
\text { general }\end{array}$ & $\begin{array}{l}\text { The focus of this study is on older people's perception of } \\
\text { telecare and care interactions within the home }\end{array}$ & None & $\begin{array}{l}\text { United } \\
\text { Kingdom }\end{array}$ \\
\hline$[40,41]$ & $\begin{array}{l}\text { Technology in } \\
\text { general, Health } \\
\text { care robots }\end{array}$ & $\begin{array}{l}\text { Study on coping strategies and technology in later life and in } \\
\text { daily activities }\end{array}$ & $\begin{array}{l}\text { Gender, age, education, } \\
\text { income, living condition }\end{array}$ & Italy \\
\hline$[43]$ & $\begin{array}{l}\text { Socially assistive } \\
\text { robots }\end{array}$ & $\begin{array}{l}\text { Psychological approach to evaluate robots in a domestic } \\
\text { setting }\end{array}$ & $\begin{array}{l}\text { Age, gender, technological } \\
\text { experience, education }\end{array}$ & Italy \\
\hline$[77]$ & RoboCare & $\begin{array}{l}\text { The focus of this study is on social interaction between users } \\
\text { and robotic agents }\end{array}$ & None & Italy \\
\hline [78] & RoboCare & $\begin{array}{l}\text { Analysis of psychological implications on the interaction } \\
\text { between the user and an assistive robotic companion }\end{array}$ & None & Italy \\
\hline$[64]$ & RoboCare, PEIS & $\begin{array}{l}\text { Comparison between elderly Italians' and Swedes' } \\
\text { perceptions of social assistive domestic robots }\end{array}$ & Age, gender, culture & Italy, Sweden \\
\hline $\begin{array}{l}{[48,51-} \\
53,79]\end{array}$ & iCat & $\begin{array}{l}\text { The five papers describe the influence of robots' social } \\
\text { abilities on elderly user's acceptance }\end{array}$ & $\begin{array}{l}\text { Gender, technological } \\
\text { experience }\end{array}$ & The Netherlands \\
\hline$[49]$ & iCat & $\begin{array}{l}\text { The objective of this study is to develop a model for } \\
\text { identifying the main influences on acceptance of socially } \\
\text { assistive robots by elderly users }\end{array}$ & None & The Netherlands \\
\hline$[17]$ & $\begin{array}{l}\text { Socially assistive } \\
\text { robots }\end{array}$ & $\begin{array}{l}\text { The focus of this study is on elderly people's health-related } \\
\text { and psychological well-being-related effects of robots }\end{array}$ & None & $\begin{array}{l}\text { Not } \\
\text { country-specific }\end{array}$ \\
\hline$[50]$ & iCat & $\begin{array}{l}\text { The study explores the acceptance of robotic technology by } \\
\text { elderly users }\end{array}$ & None & The Netherlands \\
\hline$[54]$ & RoboCare & $\begin{array}{l}\text { Focus is on the influence of various factors on the robot } \\
\text { acceptance by older adults }\end{array}$ & $\begin{array}{l}\text { Age, gender, education, } \\
\text { technological experience }\end{array}$ & The Netherlands \\
\hline$[55]$ & PeopleBot & $\begin{array}{l}\text { The study investigates if women view robots differently to } \\
\text { men }\end{array}$ & gender & USA \\
\hline$[62]$ & Assistive robots & $\begin{array}{l}\text { The paper examines which technologies persuade the elderly } \\
\text { to use them }\end{array}$ & $\begin{array}{l}\text { Technological experience, } \\
\text { family status }\end{array}$ & Finland \\
\hline$[44]$ & iRo & $\begin{array}{l}\text { The study evaluates robots for elderly and analyses the role of } \\
\text { their identity }\end{array}$ & Age, social environment & The Netherlands \\
\hline$[80]$ & Nabaztag & $\begin{array}{l}\text { The focus of this study is on acceptance and use of a social } \\
\text { robot by elderly people in a domestic setting }\end{array}$ & None & The Netherlands \\
\hline$[81]$ & HOAP-3, HRP-2 & $\begin{array}{l}\text { The study investigates people's ideas on future human-robot } \\
\text { relationships }\end{array}$ & None & Austria \\
\hline$[82]$ & $\begin{array}{l}\text { Domestic } \\
\text { robots; RoboX }\end{array}$ & $\begin{array}{l}\text { The study explores what people expect from robots and what } \\
\text { influences their perception }\end{array}$ & None & $\begin{array}{l}\text { Switzerland, } \\
\text { France }\end{array}$ \\
\hline$[83]$ & $\begin{array}{l}\text { Healthcare } \\
\text { robots }\end{array}$ & $\begin{array}{l}\text { Experts and designated users were asked to discuss future } \\
\text { visions of robotics in long-term care }\end{array}$ & None & The Netherlands \\
\hline$[45]$ & Personal robots & $\begin{array}{l}\text { The paper Investigates for whom robots should be built and } \\
\text { what they should be like }\end{array}$ & Age, gender, education & Switzerland \\
\hline [84] & $\begin{array}{l}\text { Aibo, iCat, } \\
\text { BIRON, } \\
\text { BARTHOC }\end{array}$ & $\begin{array}{l}\text { The paper reports the results of a survey on the influences of } \\
\text { appearance and abilities of social robots }\end{array}$ & $\begin{array}{l}\text { Age, technological } \\
\text { experience, profession, } \\
\text { education }\end{array}$ & Germany \\
\hline
\end{tabular}


TABle 1: Continued.

\begin{tabular}{|c|c|c|c|c|}
\hline Authors & Technology & Objective & $\begin{array}{l}\text { Sociodemographic factors } \\
\text { taken into account }\end{array}$ & Country \\
\hline$[71]$ & $\begin{array}{l}26 \text { different } \\
\text { robots }\end{array}$ & $\begin{array}{l}\text { Main objective of the paper is to give recommendations on } \\
\text { the design of robots to engineers }\end{array}$ & Age & France \\
\hline$[63]$ & Domestic robots & $\begin{array}{l}\text { The study investigates the acceptance of domestic robots by } \\
\text { younger and older adults }\end{array}$ & $\begin{array}{l}\text { Age, technological } \\
\text { experience }\end{array}$ & $\begin{array}{l}\text { Not } \\
\text { country-specific }\end{array}$ \\
\hline$[46]$ & $\begin{array}{l}\text { Medical assistive } \\
\text { robots }\end{array}$ & $\begin{array}{l}\text { The paper reports the results of two studies that focused on } \\
\text { acceptance of assistive robots in general and user diversity } \\
\text { factors in particular }\end{array}$ & $\begin{array}{l}\text { Age, gender, } \\
\text { socio-economic status }\end{array}$ & Germany \\
\hline$[66]$ & $\begin{array}{l}\text { CERO, FLO, } \\
\text { Roomba, } \\
\text { Wakamaru, } \\
\text { Aibo }\end{array}$ & $\begin{array}{l}\text { The study investigates whether the task assistance of a robot } \\
\text { relates to its social role }\end{array}$ & Age, education & Sweden \\
\hline$[85]$ & ACE Robot & $\begin{array}{l}\text { The paper discusses methodological variations for the } \\
\text { evaluation of human-robot interactions }\end{array}$ & None & Germany \\
\hline$[69]$ & Assistive robots & $\begin{array}{l}\text { This is an ethnographic study of ageing adults who live } \\
\text { independently in their homes }\end{array}$ & None & USA \\
\hline$[67]$ & $\begin{array}{l}\text { Robots in } \\
\text { general }\end{array}$ & $\begin{array}{l}\text { This study compares attitudes towards robots between } \\
\text { faculty members of an US-American and a Japanese } \\
\text { university }\end{array}$ & $\begin{array}{l}\text { Age, gender, culture, } \\
\text { education, robot related } \\
\text { experience }\end{array}$ & USA, Japan \\
\hline$[72]$ & $\begin{array}{l}\text { Assistive robots, } \\
\text { Paro }\end{array}$ & $\begin{array}{l}\text { The paper provides an overview of an evaluation of robots } \\
\text { for elderly in Denmark }\end{array}$ & None & Denmark \\
\hline$[47]$ & Charles & $\begin{array}{l}\text { The authors investigated age and gender factors in user } \\
\text { acceptance of health care robots }\end{array}$ & $\begin{array}{l}\text { Age, gender, culture, } \\
\text { technological experience }\end{array}$ & New Zealand \\
\hline$[68]$ & Assistive robot & $\begin{array}{l}\text { The study analyses the reactions of retirement village } \\
\text { residents and staff to a health-care robot }\end{array}$ & Technological experience & New Zealand \\
\hline
\end{tabular}

Full citations of the included studies are in the List of Reference.

young people tended to adopt a trial and error strategy, adults read the instructions, and older persons wanted to ask experts. Unlike young people and adults, older persons showed a more negative emotional response towards robots. The elderly preferred small-size robots with a feminine voice that move slowly and only assist them with their tasks. They wanted robots with limited autonomy because they thought they were safer. They were not aware of the robots' cognitive abilities. The study found that older people were more reluctant and opposed to technological change and had a lower level of technological literacy. However, these findings are based on empirical research and were not "constructed" by the authors. Hence, the findings support constructed user representations of older people as described by Neven [7, 9]. If such results constitute the basis for decisions on robot design, they can yield a distorted picture as the tested persons are not representative of older adults in general. The problem that their passivity is misinterpreted may arise.

In a recent paper, Neven [44] described a study, in which a robot designed to enhance the health of elderly persons was tested. He participated as observer in tests of a large research laboratory where the interactions between the robot, the elderly test users, and the robot designers were analysed to examine how views of older persons, age in general, and definitions of health shape the development of technologies. This was tested in two settings. In the first experiment, the elderly test users interacted with a robot (iRo) in a laboratory setting. In the second experiment, they tested the robot at home for two weeks. The data collected by the iRo were subsequently analysed. Beer et al. [24] also found that designers of such devices categorised old people according to their preferences, needs, lifestyles, mental and physical abilities, and social environments. However, the older persons were selected according to their age and because of the fact that they lived alone. Moreover, the iRo had been shown in the media and advertised as a robot that helps lonely and older people shortly before the experiments. This negatively influenced the elderly test users. Although they liked to interact with the robot, they did not want to be labelled as old persons who are housebound, old, lonely, feeble, and in need of care and attention. Neven conclude that it is important how robots are advertised. If the designers equate elderly with old, frail, and so forth, there is a higher likelihood that older people will reject the technology. As this is part of the ageing-and-innovation discourse $[7,9]$, it is important to reconsider the definition of age or dependence. It is also important to note that older adults are not passive consumers but active test users.

Arras and Cerqui [45] surveyed a sample of 2042 to find out if people are ready to share their lives with a robot. They found that the majority of elderly people do not think that robotics can contribute to their personal happiness. However, although they are the age group least willing to share their life with a robot, they would accept to do so if they are no longer able to perform their daily tasks, because this would make them more independent and the robot would improve their quality of life. Hence the authors conclude that a misunderstanding of the terms "autonomy" 
or "independence" could be fatal for the acceptance of robots in care settings [45]. This shows that they are aware of the fact that constructed user needs are the wrong approach for evaluating technology with older persons. It also documents that old age does not relate to constructed or assumed dependence.

Mitzner et al. [32] found that older adults have more positive than negative attitudes towards the technologies they currently use. This contradicts stereotypes that older adults are afraid or unwilling to use technical devices. The authors conclude that their findings also highlight how important perceived advantages and ease of use are for models of technology acceptance.

Gaul et al. [46] found that a positive attitude as well as technical experience and a positive evaluation of the robot decrease with increasing age. These different findings and conclusions demonstrate the complexity of the interactions between age and such other factors as experience with technology. They also highlight how important it is not to adhere to stereotype user representations.

6.3. Gender. Scopelliti et al. [43] came to the conclusion that gender makes a difference in the acceptance of assistive robotic technologies. Women are more sceptical and afraid of becoming dependent. When interacting with the robot, they prefer a greater distance between them and the robot while men find robots that walk around the house more amusing. They like the eye contact and the robot's ability to act autonomously whereas women think it is strange to talk to a nonhuman device. With regard to activeness, also Bemelmans et al. [38] note that the robot NeCoRo is more positively evaluated by men because they like the active behaviour of this robotic cat more than women. In general, Kuo et al. [47] found that males had a more positive attitude than females with regard to the usefulness of healthcare robots and towards the possibility of using them in the future. Picturing women as rather passive and men as active is part of a script which tends to conceptualise older technology users [10, 12-14]. Constructing devices based on such a script would be a fatal mistake.

Heerink et al. did a series of studies on the socially assistive robot iCat and robotic agents. They studied the acceptance [48-50] of a robotic agent by elderly users, the influence of social presence on the acceptance [51], the conversational expressiveness of elderly users interacting with the robot and a screen agent [52], and the influence of the robot's social abilities on the acceptance by elderly users [53]. They found remarkable differences with regard to gender: men are more eager than women in wanting the robot if it were available immediately [48, 51]. Male participants have significantly more experience with computers. The authors conclude that this might explain why they are more prepared to use a robot immediately. In a recent paper [54], the influence of age, gender, education, and computer experience on older adults' robot acceptance was analysed. When studying gender differences, the authors found significant proof for experience and perceived ease of use, which showed that male-and probably also femaleparticipants who are more familiar with computers are more likely to perceive the robot as an easy to use technology. This documents how important it is to consider interaction effects between various sociodemographic factors, in this case gender and technological experience.

Schermerhorn et al. [55] explicitly addressed gender issues in connection with the social presence of a robot. They studied the interaction between humans and a robot that is capable of asking questions. Women and men had to do arithmetic tasks in the presence of the robot and were interviewed by the researchers afterwards. The authors noted persistent differences between males and females with respect to their ratings of the robot. This might be due to the fact that the voice of the robot was male, which may have caused women to be more collaborative as they took the robot to be the opposite sex. Male participants regarded the robot as a peer and thus were more competitive. In a postexperimental survey, the authors discovered that men tend to anthropomorphise the robot because, unlike women, they perceive it more like an autonomous person [55]. According to the authors, the gender differences in the perception of the robot can also be explained by the gender and context-based priming hypothesis, which implies that males and females have different preperceptions of robots. This affects their interactions. The authors conclude that it is important for the long-term acceptance to consider genderspecific presumptions about robots when designing them along with other important factors such as the robot's voice [55]. Once more, the notion of the script becomes evident. The differences are ascribed to gender per se and the objective is to design robots that meet the needs of users as they are perceived and interpreted by the researchers.

Arras and Cerqui [45] did a larger survey with 2042 participants from all age groups. The analysis showed that women seem much less likely to accept robot technologies in their daily lives than men. Perceptions are also biased by science fiction robots, which are more popular with men. Another explanation for men's more positive attitude towards robots might be the fact that they are made by men [45]. The authors offer several generalised explanations why women are less likely to accept robot technologies, but none of them can be tested in such a setting. Thus the notion of script and the construction of user needs also play a role in this context $[7,9,12]$.

In a recent study, Gaul et al. [46] found that gender differences related to perceived usefulness of assistive technologies are likely to disappear. For robots that monitor health parameters, the authors also noted that women were more conscientious when it came to monitoring their health parameters on a regular basis. Men were less diligent in this respect. This might be related to the hypothesis that women in general are more health conscientious [56-61]. Hence it is not surprising that women tend to be more meticulous when it comes to health monitoring by an assistive device.

Concerning the interrelation between gender and technological experience, Gaul et al. [46] found that men's technological expertise was significantly higher than that of women. With regard to acceptance they noted that, for both men and women, incentives and barriers are important elements in explaining their intention to use such devices. 
6.4. Education and Technological Experience. As various research papers report that education and technological experience have an impact on robot acceptance, it is important to consider these factors when designing such devices. In their research about people's attitudes, Scopelliti et al. [43] found that the effect of education was significant for the variable "negative feelings". Persons with lower education reported more negative feelings than people who had completed high school and a degree.

With regard to robot perception, Heerink [54] noted that education correlates with perceived sociability: the more educated participants were, the less open they were to perceiving the robot as a social entity. The study also confirmed that perceived ease of use is linked to people's technological experience.

Also Sorri and Leinonen [62] found that elderly persons who are more easily persuaded to use assistive technologies have more prior experience with technologies. This study is yet another proof of interaction effects and confirms that the ability to learn how to manage assistive devices also influences acceptance. Depressed mood, tiredness, and decreasing cognitive skills herald a lower preparedness to use assistive devices, because they affect people's initiative spirit, learning abilities, and concentration.

Ezer et al. [63] found that acceptance is also influenced by the perceived advantages offered by robots. When elderly persons do not find the robot useful, they are less likely to accept it in their home. It is important to emphasise the advantages and to introduce educational programmes to teach elderly persons and caregivers how to use the robotic devices. This may increase the use of such technological devices in the future [32].

6.5. Family Status. Cortellessa et al. [64] note that elderly people living with their partner find robots for their personal safety or for reminding them of daily activities (e.g., taking their medicine) more acceptable than people who live on their own. Sorri and Leinonen [62] did a qualitative study on users' experience. They asked which technologies are attractive for elderly people, which kinds of use they consider interesting, and which factors are involved in selecting an appliance. They found that the healthier spouses are less likely to accept a technological device at home, because they fear that their partners with physical or mental limitations become frustrated when they are not able to handle the device. This underlines how important it is to build assistive robots that can also easily be used by persons with reduced abilities.

This is a justified concern, because Milligan et al. [65] noted that older mentally impaired persons often reject or misuse devices and expect them to do more than they actually can do. Among other things, they also want to socially communicate with their devices. The authors conclude that current devices are not adequately designed to meet the needs of frail older people who might experience memory loss due to dementia.

Mahani and Eklundh [66] investigated the link between a task-assistance robot and its social role. In 21 semistructured qualitative interviews, they asked seven persons aged 36-85 with moderate motion impairments and 14 people aged 23-70 with severe, moderate, and no motion impairment. The results indicate that persons with either partial, severe, or temporary motion impairments, who are embedded in a family, might be more inclined to have robots as mere tools. The study also shows that persons who live on their own are more inclined to have a robot with social abilities [66]. This once more shows how important it is to give older persons an assistive robot that fits their personal needs in line with their specific sociodemographic backgrounds and requirements.

6.6. Cultural Background. Several studies analysed how the cultural background (as defined by the national level) might influence the acceptance of assistive robotic technologies. Cortellessa et al. [64] focused on a comparison between Italian and Swedish older persons with regard to their perceptions of socially assistive domestic robots. They showed 40 Italians and 43 Swedes eight short movies with different scenarios of robots in domestic settings. In general, the evaluation of both groups was positive. They rated the robot's abilities to avoid obstacle and to directly communicate positively, noted that people might feel safer, and thought the robot could reduce problems caused by age-related impairments. Italians and Swedes had the same preferences regarding the physical aspects of the robot. They wanted a robot with less-human-like attributes and considered it useful for emergency-related tasks. The results also suggest that the living conditions are an important factor for assessing the acceptance of robotic assistive technologies in a cross-cultural perspective: In Sweden more people live alone and the participants stated that a robot might violate their privacy, while this was not an issue for the Italian respondents. The Swedish respondents also worried that they might become dependent on the robot [64].

MacDorman et al. [67] analysed the attitudes towards assistive robotics among the faculty members of a US and a Japanese university. The similarity of results suggests that, despite the media's hype about Japan's robot "craze", factors other than attitude are more important for explaining the acceptance of robots. These include differences in history and religion, personal and human identity, economic structure, professional specialisation, and government policy. The authors state that Japan's philosophical doctrines, that is, Shinto, Buddhism, and neo-Confucianism, have never impeded the country's progress in science and technology in the way the Catholic influence did in western societies. In the western world, human beings are considered unique. This ideology is deeply rooted in religious traditions. Thus, in Japan, humanoid robots are more accepted than in western societies. In addition, robots have played an important role in Japan's manufacturing industries and are a key component of government plans to address labour shortages in health care and elder care [67].

\section{Discussion}

The literature review showed that sociodemographic factors play an important role in the acceptance of robotic assistive 
technologies. However, many researchers, designers, and engineers do not take these differences into account although they are aware of this weakness. They argue that it is difficult to investigate these factors with small sample sizes. In addition, studies tend to focus on testing prototypes and not on indicating relevant sociodemographic factors.

It is important to mention that the studies are rooted in various disciplines and methodologies. They offer technical, sociological, and psychological viewpoints. This is decisive for the way, in which sociodemographic factors are considered. For example, qualitative studies and (socio)psychological studies are more open to investigating other factors whereas quantitative studies relying on existing scales are more restrictive in exploring new factors. However, as this paper did not exclude studies because of their methodological approach or different disciplines, this cannot be criticised on a general level. Working with interdisciplinary research teams might therefore be helpful; especially in technical studies and scenarios designed to test technical products with older users, it is vital to include social scientists because they can make valuable suggestions on how to avoid stereotyping or constructing inaccurate user needs.

During the search process it became clear that approaches are rather diversified because methods are often adapted for the specific robot that is evaluated. As the robots are very different, a more uniform approach is difficult [54]. Another issue is robots that are not directly presented but only shown on videos or pictures. This influences the perception since the situations shown in the videos are not comparable to tests where older persons can actually use the robot. Broadbent and Stafford [68], for example, found that the attitudes towards a robot improved after people had interacted with it. We may assume that the more research will be done, the more methods will be developed. If researchers rely on existing approaches such as technology acceptance models, taking into account sociodemographic factors in their work remains an issue. Heerink [54] included moderating factors in his empirical model (age, gender, education, and computer experience) and argued that future research should use a complete inventory comprising various influence factors. The assumption is that, in addition to sociodemographic variables, there is a plethora of moderating factors (e.g., physical and mental condition, self-directed use, living conditions, decline of cognitive skills, depressed mood) or such short-term factors as tiredness [43, 62]. As we have seen, these factors remain unconsidered because the sample sizes are often too small to permit robust statistical correlation tests.

With regard to the methodological variety of earlier research efforts, the study by Scopelliti et al. [43] showed that the results of a qualitative explorative pilot study are very useful for designing the quantitative questionnaire. Moreover, this inductive approach offers deeper insights into the feelings and perceptions of older adults towards robotic technologies. The results might reveal other important factors for understanding acceptance and usage patterns. Quantitative research can then include these factors and test them with larger sample sizes to study correlations and interaction effects.
Attention should also be paid to factors related to demographic change. It is important to note that studies which explore differences between young and older age groups and studies that look for differences between young and old elderly [51] must be interpreted differently because the generations familiar with modern technologies will be the main target group in approximately 15 to 20 years. The more experienced people are with technology, and the smarter the devices, the higher might be their willingness to use them when they need them.

Another issue is stereotypes about ageing, gender, or other sociodemographic factors that might influence the design process $[7,44]$. The views of the elderly testers may not match those of the designers of such robots. Forlizzi et al. [69] evaluated the needs of designated users directly in their home settings. This is a good solution because it permits adapting assistive technologies to the users' individual needs. However, the procedure should be repeated at regular intervals to take into account changes in people's housing and living conditions. Neven also mentions the valuable contributions of ethnographic studies and states that this type of research [70] permits deeper insights into the way older adults interact with new technology in their environments [7].

The literature review also revealed other interesting sociodemographic factors that influence the acceptance of assistive robots. Religious and cultural backgrounds play a role in this context $[45,67]$. This becomes particularly evident in evaluations of the physical appearance of robots. Religious and older people seem to dislike a human-like appearance. In a recent study, Wu et al. [71] found that the older people are, the lower is the likelihood that they accept the humanoid appearance of a robot. This might be due to the fact that older persons tend to be more religious than younger ones. Hence it would be important to include the religious background in upcoming research.

The results of the review also show that such aspects as humanoid versus nonhumanoid appearance have a large influence on the acceptance of robots. Examples of other attributes are that robots should be lightweight and also function outside the home [69]. They should not make much noise as Hansen et al. [72] suggest. However, the influence of specific attributes is not part of this paper. More information on this detail can be found in the publication of Broadbent et al. [2]. Moreover, the phenomenon of the uncanny valley described by Mori [73] is an important factor in this context.

Finally, and this is the most striking result of this paper, it is very important to consider the interactions between different sociodemographic factors and how they are related to other factors such as experience with technology, ease of use, and felt needs. The users' previous experience with technology seems to be decisive for the acceptance. It can be hypothesised that experience with technology might be a moderating factor of such sociodemographic variables as age, gender, and education. Younger persons might accept robots more easily because they are more familiar and experienced with modern technologies than older persons. A recent study by Ezer et al. [63] confirms this hypothesis. 
They found that younger and older adults with comparable technological experience have similar expectations of robots. Thus it is important to familiarise older persons with technical possibilities as this affects their acceptance of assistive devices.

The mediating effect of experience with technology may also hold true with respect to gender, because men are more familiar with technology than women $[31,35]$ and thus might also be more likely to accept robots. It was shown that, when women are more experienced with technology, their acceptance level of using assistive robotic devices is higher and the effect of gender decreases [46, 48, 51, 54]. A good approach related to this prevalence is to specifically address women when promoting technological products and their benefits. Less educated persons also seem to be less experienced with technology $[31,34,36]$. A precondition for implementing assistive technologies is thus to take this fact into account which leads us to the next moderating factor, namely, the perceived ease of use. The more people feel that a device is easy to use, the higher is their acceptance level. This also mitigates the influence of sociodemographic factors. However, in people with lower education, difficult use reinforces negative acceptance patterns. This should be avoided by designing easy to use technologies and/or providing good technical training and assistance. Access to technology should not be limited to more educated and technologically experienced persons. The problem is, however, that designers lack insight into what older people find easy to use.

When analysing robot acceptance, user representations and the ageing-and-innovation discourse (Neven) play an important role. In most studies, the ageing of the population is presented as a problem which can be mitigated by the introduction of socially assistive robotics. However, when examining the various studies, it becomes evident that the development of these technologies is in an early stage and that they are not yet available on the mass market. The following suggestions show how the critical insights of the review could assist robotics designers.

The results clearly demonstrate how important it is to take into account sociodemographic factors when evaluating the acceptance of socially assistive robots by older persons. As these factors are interrelated, their influence is very complex. Moreover, the impact of moderating factors (e.g., experience with technology) must also be considered. A good empirical approach would be to secure sufficient funding for testing acceptance with large sample sizes over longer periods of time. As the demographic change and the progressively improving quality of assistive robots have an impact on perceptions and acceptance patterns, longitudinal studies are also highly recommended. Moreover, studies should use a consistent methodology in order to be comparable. A triangulation $[43,59,74]$ of qualitative and quantitative studies could also be useful because it promises deeper insights into various needs, perceptions, and acceptance patterns of older persons. To avoid the pitfall of stereotyping older adults based on discourses about age, it is vital to combine insights from (feminist) gerontology and science and technology studies. According to Joyce and Mamo [75] "a critical analysis of the way ageing and technology are co-constructed thus explicitly includes the study of the way in which technologies for older people are designed and how older users are represented in those processes". Another approach could be to study persons in their home settings before confronting them with technologies. This puts the focus on the individuals, their sociodemographic background, and (socio)psychological factors, for example, on their needs or technological experience. It is vital to involve prospective users in the design process as active testers. Their opinions and perceptions will help researchers, designers, and engineers to create a product that fits their special demands.

\section{Conflict of Interests}

The author declares that there is no conflict of interests.

\section{Acknowledgments}

The author wants to thank four anonymous reviewers for their helpful reviews, literature suggestions, and useful comments and Marc Luy and Christian Wegner for their valuable remarks on the first version of the paper. She is grateful to Sylvia Trnka for language editing of the paper. The research reported in this paper was part of a larger project (living independently at home-a feasibility study about assistive technology for elderly persons in Europe) funded by the Austrian Academy of Sciences.

\section{References}

[1] W. Lutz, W. Sanderson, and S. Scherbov, "The coming acceleration of global population ageing," Nature, vol. 451, no. 7179, pp. 716-719, 2008.

[2] E. Broadbent, R. Stafford, and B. MacDonald, "Acceptance of healthcare robots for the older population: review and future directions," International Journal of Social Robotics, vol. 1, pp. 319-330, 2009.

[3] K. Wada, T. Shibata, T. Saito, and K. Tanie, "Effects of robot assisted activity to elderly people who stay at a health service facility for the aged," in Proceedings of the IEEE International Conference on Intelligent Robots and Systems, vol. 3, pp. 28472852, 2003.

[4] J. Sasaki, K. Yamada, M. Tanaka, and Y. Funyu, "An experiment of the life support network for elderly people living in a rural area," in Proceedings of the 7th WSEAS International Conference on Applied Computer Science, vol. 7, pp. 316-321, World Scientific and Engineering Academy and Society (WSEAS), Venice, Italy, 2007.

[5] Computing Community Consortium, A Roadmap for Us Robotics: From Internet to Robotics, CRA Computing Research Association, 2009.

[6] W. C. Sanderson and S. Scherbov, "Remeasuring aging," Science, vol. 329, no. 5997, pp. 1287-1288, 2010.

[7] L. B. M. Neven, "Representations of the old and ageing in the design of the new and emerging: assessing the design of ambient intelligence technologies for older people," Enschede, p. $228,2011$.

[8] N. Oudshoorn and T. Pinch, "Introduction: how users and non-users matter," in How Users Matter; The Co-Construction 
of Users and Technologies, N. P. Oudshoorn and T. Pinch, Eds., MIT Press, Cambridge, Mass, USA, 2003.

[9] A. Peine and L. Neven, "Social-structural lag revisited," Gerontechnology, vol. 10, no. 3, pp. 129-139, 2011.

[10] M. Akrich, "The de-scription of technical objects," in Shaping Technology/Building Society: Studies in Sociotechnical Change, W. L. Bijker, Ed., pp. 205-224, MIT Press, Cambridge, Mass, USA, 1992.

[11] B. Latour, Pandora's Hope: Essays on the Reality of Science Studies, Harvard University Press, Cambridge, Mass, USA, 1999.

[12] N. Oudshoorn, "Genderscripts in technnologie. Noodlot of uitdaging?" Tijdschrift voor Vrouwenstudies, vol. 17, pp. 350367, 1996.

[13] N. Oudshoorn, The Male Pill, a Biography of a Technology in the Making, Duke University Press, London, UK, 2003.

[14] E. V. Oost, "Materializes gender: how shavers configure the users' femininity and masculinity," in How Users Matter; The Co-Construction of Users and Technologies, N. P. Oudshoorn and P. Trevor, Eds., MIT Press, Cambridge, Mass, USA, 2003.

[15] G. Fourez, "Scientific and technological literacy as a social practice," Social Studies of Science, vol. 27, no. 6, pp. 903-936, 1997.

[16] S. Petrina, "Politics of technological literacy," International Journal of Technology and Design Education, vol. 10, no. 2, pp. 181-206, 2000.

[17] J. Broekens, M. Heerink, and H. Rosendal, "Assistive social robots in elderly care: a review," Gerontechnology, vol. 8, pp. 94-103, 2009.

[18] D. Feil-Seifer and M. J. Mataric, "Defining socially assistive robotics," in Proceedings of the IEEE 9th International Conference on Rehabilitation Robotics, Chicago, Ill, USA, 2005.

[19] K. Wada and T. Shibata, "Living with seal robots-its sociopsychological and physiological influences on the elderly at a care house," IEEE Transactions on Robotics, vol. 23, no. 5, pp. 972-980, 2007.

[20] K. Wada and T. Shibata, "Social and physiological influences of robot therapy in a care house," Interaction Studies, vol. 9, no. 2, pp. 258-276, 2008.

[21] K. Wada, T. Shibata, T. Musha, and S. Kimura, "Robot therapy for elders affected by dementia," IEEE Engineering in Medicine and Biology Magazine, vol. 27, no. 4, pp. 53-60, 2008.

[22] T. Nomura, "Consideration of mental therapeutic robots from psychological and sociological perspectives," in Laboratories $A I R a C$, Department of Media Informatics, Ryukoku University, Kyoto, Japan, 2006.

[23] A. Haasch, S. Hohenner, S. Hüwel et al., "Biron-the bielefeld robot companion," in Proceedings of the International Workshop on Advances in Service Robots, Stuttgart, Germany, 2004.

[24] J. M. Beer, A. Prakash, T. L. Mitzner, and W. A. Rogers, "Understanding robot acceptance," in Technology GIo, School of Psychology, Human Factors and Aging Laboratory, Atlanta, Ga, USA, 2010.

[25] S. G. Green, M. B. Gavin, and L. Aiman-Smith, "Assessing a multidimensional measure of radical technological innovation," IEEE Transactions on Engineering Management, vol. 42, no. 3, pp. 203-214, 1995.

[26] R. D. Dewar and J. E. Dutton, "The adoption of radical and incremental innovations-an empirical-analysis," Management Science, vol. 32, pp. 1422-1433, 1986.

[27] F. D. Davis, "Perceived usefulness, perceived ease of use, and user acceptance of information technology," Management Information Systems, vol. 13, no. 3, pp. 319-339, 1989.
[28] V. Venkatesh and F. D. Davis, "Theoretical extension of the technology acceptance model: four longitudinal field studies," Management Science, vol. 46, no. 2, pp. 186-204, 2000.

[29] V. Venkatesh, M. G. Morris, G. B. Davis, and F. D. Davis, "User acceptance of information technology: oward a unified view," Management Information Systems, vol. 27, no. 3, pp. 425-478, 2003.

[30] R. P. Bagozzi, F. D. Davis, and P. R. Warshaw, "Development and test of a theory of technological learning and usage," Human Relations, vol. 45, pp. 659-686, 1992.

[31] H. Sun and P. Zhang, "The role of moderating factors in user technology acceptance," International Journal of Human Computer Studies, vol. 64, no. 2, pp. 53-78, 2006.

[32] T. L. Mitzner, J. B. Boron, C. B. Fausset et al., "Older adults talk technology: technology usage and attitudes," Computers in Human Behavior, vol. 26, no. 6, pp. 1710-1721, 2010.

[33] J. A. G. M. van Dijk, "Digital divide research, achievements and shortcomings," Poetics, vol. 34, no. 4-5, pp. 221-235, 2006.

[34] S. J. Czaja, N. Charness, A. D. Fisk et al., "Factors predicting the use of technology: findings from the Center for Research and Education on Aging and Technology Enhancement (CREATE)," Psychology and Aging, vol. 21, no. 2, pp. 333-352, 2006.

[35] V. Venkatesh and M. G. Morris, "Why don't men ever stop to ask for directions? Gender, social influence, and their role in technology acceptance and usage behavior," Management Information Systems, vol. 24, no. 1, pp. 115-136, 2000.

[36] M. Fishbein and I. Ajzen, Beliefs, Attitude, Intention and Behavior: An Introduction to Theory and Research, AddisonWesley, Reading, Mass, USA, 1975.

[37] R. D. Ellis and J. C. Allaire, "Modeling computer interest in older adults: the role of age, education, computer knowledge, and computer anxiety," Human Factors, vol. 41, no. 3, pp. 345$355,1999$.

[38] R. Bemelmans, G. J. Gelderblom, P. Jonker, and L. Witte, “The potential of socially assistive robotics in care for elderly, a systematic review," in Human-Robot Personal Relationships, M. H. Lamers and F. J. Verbeek, Eds., vol. 59, pp. 83-89, Springer, Berlin, Germany, 2011.

[39] R. Bemelmans, G. J. Gelderblom, P. Jonker, and L. de Witte, "Socially assistive robots in elderly care: a systematic review into effects and effectiveness," Journal of the American Medical Directors Association, vol. 13, no. 2, pp. 114-120, 2012.

[40] M. V. Giuliani, M. Scopelliti, and F. Fornara, "Coping strategies and technology in later life," in Proceedings of the Symposium on Robot Companions SSAISB Convention, pp. 4653, Hatfield, UK, 2005.

[41] M. V. Giuliani, M. Scopelliti, and F. Fornara, "Elderly people at home: technological help in everyday activities," in Proceedings of the IEEE International Workshop on Robot and Human Interactive Communication, vol. 2005, pp. 365-370, Nashville, Tenn, USA, 2005.

[42] C. McCreadie and A. Tinker, "The acceptability of assistive technology to older people," Ageing and Society, vol. 25, no. 1, pp. 91-110, 2005.

[43] M. Scopelliti, M. V. Giuliani, and F. Fornara, "Robots in a domestic setting: a psychological approach," Universal Access in the Information Society, vol. 4, no. 2, pp. 146-155, 2005.

[44] L. Neven, "'But obviously not for me': robots, laboratories and the defiant identity of elder test users," Sociology of Health and Illness, vol. 32, no. 2, pp. 335-347, 2010.

[45] K. O. Arras and D. Cerqui, "Do we want to share our lives and bodies with robots?" Tech. Rep. 0605-001, Swiss Federal Institute of Technology, Lausanne, Switzerland, 2005. 
[46] S. Gaul, W. Wilkowska, and M. Ziefle, "Accounting for user diversity in the acceptance of medical assistive technologies," in Proceedings of the 3rd International ICST Conference on Electronic Healthcare for the 21st Century, Casablanca, Morocco, 2010.

[47] I. H. Kuo, J. M. Rabindran, E. Broadbent et al., "Age and gender factors in user acceptance of healthcare robots," in Proceedings of the 18th IEEE International Symposium on Robot and Human Interactive (ROMAN '09), pp. 214-219, Toyama, Japan, October 2009.

[48] M. Heerink, B. Kröse, V. Evers, and B. Wielinga, "Studying the acceptance of a robotic agent by elderly users," International Journal of Assistive Robotics and Mechatronics, vol. 7, pp. 3342, 2006.

[49] M. Heerink, B. Kröse, V. Evers, and B. Wielinga, "Assessing acceptance of assistive social agent technology by older adults: the almere model," International Journal of Social Robotics, vol. 2, pp. 361-375, 2010.

[50] M. Heerink, B. Kröse, B. Wielinga, and V. Evers, "Enjoyment intention to use and actual use of a conversational robot by elderly people," in Proceedings of the 3rd ACM/IEEE International Conference on Human-Robot Interaction (HRI '08), pp. 113-119, March 2008.

[51] M. Heerink, B. Kröse, V. Evers, and B. Wielinga, "The influence of social presence on acceptance of a companion robot by older people," Journal of Physical Agents, vol. 2, pp. 33-40, 2008.

[52] M. Heerink, B. Kröse, V. Evers, and B. Wielinga, "Observing conversational expressiveness of elderly users interacting with a robot and screen agent," in Proceedings of the IEEE 10th International Conference on Rehabilitation Robotics (ICORR '07), pp. 751-756, Noordwijk, The Netherlands, June 2007.

[53] M. Heerink, B. Kröse, V. Evers, and B. Wielinga, "The influence of a robot's social abilities on acceptance by elderly users," in Proceedings of the 15th IEEE International Symposium on Robot and Human Interactive Communication (ROMAN '06), pp. 521-526, Hertfordshire, UK, 2006.

[54] M. Heerink, "Exploring the influence of age, gender, education and computer experience on robot acceptance by older adults," in Proceedings of the 6th ACM/IEEE International Conference on Human-Robot Interaction (HRI '11), pp. 147148, Lausanne, Switzerland, 2011.

[55] P. Schermerhorn, M. Scheutz, and C. R. Crowell, "Robot social presence and gender: do females view robots differently than males?" in Proceedings of the 3rd ACM/IEEE International Conference on Human-Robot Interaction (HRI '08), pp. 263270, Amsterdam, The Netherlands, March 2008.

[56] W. H. Courtenay, "Constructions of masculinity and their influence on men's well-being: a theory of gender and health," Social Science and Medicine, vol. 50, no. 10, pp. 1385-1401, 2000.

[57] I. Waldron, "Trends in gender differences in mortality: relationships to changing gender differences in behaviour and other causal factors," in Gender Inequality in Health, E. Annandale and K. Hunt, Eds., pp. 150-181, Open University Press, Buckingham, UK, 2000.

[58] P. Flandorfer and K. Fliegenschnee, "The gender gap in life expectancy in Austria: theoretical considerations based on a qualitative grounded theory study," Journal of Public Health, vol. 19, no. 5, pp. 481-494, 2011.

[59] P. Flandorfer, C. Wegner, and I. Buber, "Gender roles and smoking behaviour,” VID Working Paper, pp. 1-25, 2010.
[60] L. M. Verbrugge, "Gender and health: an update on hypotheses and evidence," Journal of Health and Social Behavior, vol. 26, no. 3, pp. 156-182, 1985.

[61] N. Krieger, "Genders, sexes, and health: what are the connections-and why does it matter?" International Journal of Epidemiology, vol. 32, no. 4, pp. 652-657, 2003.

[62] L. Sorri and E. Leinonen, "Technology that persuades the elderly," in Persuasive Technology, $\mathrm{H}$ Oinas-Kukkonen, P. Hasle, M. Harjumaa, K. Segerståhl, and P. Øhrstrøm, Eds., vol. 5033, pp. 270-273, Springer, Berlin, Germany, 2008.

[63] N. Ezer, A. Fisk, and W. Rogers, "Attitudinal and intentional acceptance of domestic robots by younger and older adults," in Universal Access in Human-Computer Interaction Intelligent and Ubiquitous Interaction Environments, C. Stephanidis, Ed., vol. 5615, pp. 39-48, Springer, Berlin, Germany, 2009.

[64] G. Cortellessa, M. Scopelliti, L. Tiberio, G. K. Svedberg, A. Loutfi, and F. Pecora, "A cross-cultural evaluation of domestic assistive robots," in Proceedings of the AAAI Fall Symposium on AI in Eldercare: New Solutions to Old Problems, pp. 24-31, Arlington, Tex, USA, 2008.

[65] C. Milligan, C. Roberts, and M. Mort, "Telecare and older people: who cares where?” Social Science and Medicine, vol. 72, pp. 347-354, 2011.

[66] M. Mahani and K. S. Eklundh, "A survey of the relation of the task assistance of a robot to its social role," in Communication $K C S a$, Royal Institute of Technology, Stockholm, Sweden, 2009.

[67] K. F. MacDorman, S. K. Vasudevan, and C. C. Ho, "Does Japan really have robot mania? Comparing attitudes by implicit and explicit measures," AI and Society, vol. 23, no. 4, pp. 485-510, 2009.

[68] L. Broadbent and R. Stafford, "Retirement village residents" and staff reactions to a healthcare robot: user trial 1," Faculty of Engineering, University of Auckland, 2011.

[69] J. Forlizzi, C. DiSalvo, and F. Gemperle, "Assistive robotics and an ecology of elders living independently in their homes," Human-Computer Interaction, vol. 19, no. 1-2, pp. 25-59, 2004.

[70] M. S. Lie and K. H. Sørensen, in Making Technology our Own? Domesticating Technology into Everyday Life, Scandinavian University Press, Oslo, Norway, 1996.

[71] Y.-H. Wu, C. Fassert, and A.-S. Rigaud, "Designing robots for the elderly: appearance issue and beyond," Archives of Gerontology and Geriatrics, vol. 54, no. 1, pp. 121-126, 2012.

[72] S. T. Hansen, H. J. Andersen, and T. Bak, "Practical evaluation of robots for elderly in Denmark-an overview," in Proceedings of the 5th ACM/IEEE International Conference on HumanRobot Interaction (HRI '10), pp. 149-150, March 2010.

[73] M. Mori, “The uncanny valley," Energy, vol. 7, pp. 33-35, 1970.

[74] W. K. Olsen, "Triangulation in social research: qualitative and quantitative methods can really be mixed," in Developments in Sociology, M. Haralambos and M. Holborn, Eds., Causeway Press, Ormskirk, UK, 2004.

[75] K. Joyce and L. Mamo, "Graying the cyborg; new directions in feminist analyses of aging, science, and technology," in Age Matters; Realigning Feminist Thinking, T. S. Calasanti and K. F. Slevin, Eds., Taylor \& Francis Group, London, UK, 2006.

[76] R. Looije, M. A. Neerincx, and F. Cnossen, "Persuasive robotic assistant for health self-management of older adults: design and evaluation of social behaviors," International Journal of Human Computer Studies, vol. 68, no. 6, pp. 386-397, 2010.

[77] A. Cesta, G. Cortellessa, V. Giuliani et al., "Proactive assistive technology: an empirical study," in Proceedings of the INTERACT, pp. 255-268, Springer, Rio de Janeiro, Brazil, 2007. 
[78] A. Cesta, G. Cortellessa, M. V. Giuliani, F. Pecora, M. Scopelliti, and L. Tiberio, "Psychological implications of domestic assistive technology for the elderly," PsychNology Journal, vol. 5, pp. 229-252, 2007.

[79] M. Heerink, B. Kröse, B. Wielinga, and V. Evers, "Humanrobot user studies in eldercare: lessons learned," in Proceedings of the ICOST, pp. 31-38, Belfast, Northern Ireland, 2007.

[80] T. Klamer and S. B. Allouch, "Acceptance and use of a social robot by elderly users in a domestic environment," in Proceedings of the 4th International Conference on Pervasive Computing Technologies for Healthcare, Pervasive Health, Munich, Germany, 2010.

[81] A. Weiss, J. Igelsböck, D. Wurhofer, and M. Tscheligi, "Looking forward to a "robotic society"? notions of future human-robot relationships," International Journal of Social Robotics, vol. 3, pp. 1-8, 2010.

[82] C. Ray, F. Mondada, and R. Siegwart, "What do people expect from robots?" in Proceedings of the IEEE/RSJ International Conference on Intelligent Robots and Systems (IROS '08), pp. 3816-3821, Nice, France, September 2008.

[83] A. van der Plas, M. Smits, and C. Wehrmann, "Beyond speculative robot ethics: a vision assessment study on the future of the robotic caretaker," Accountability in Research, vol. 17, no. 6, pp. 299-315, 2010.

[84] M. Lohse, F. Hegel, and B. Wrede, "Domestic applications for social robots - an online survey on the influence of appearance and capabilities," Journal of Physical Agents, vol. 2, pp. 21-32, 2008.

[85] A. Weiss, R. Bernhaupt, M. Tscheligi, D. Wollherr, K. Kühnlenz, and M. Buss, "A methodological variation for acceptance evaluation of human-robot interaction in public places," in Proceedings of the 17th IEEE International Symposium on Robot and Human Interactive Communication (ROMAN '08), pp. 713-718, Munich, Germany, August 2008. 


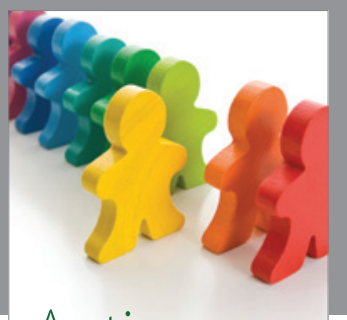

Autism

Research and Treatment
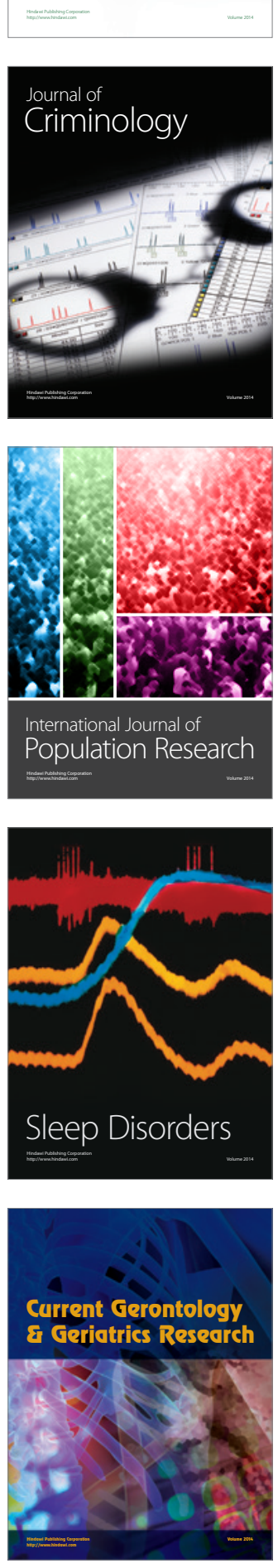
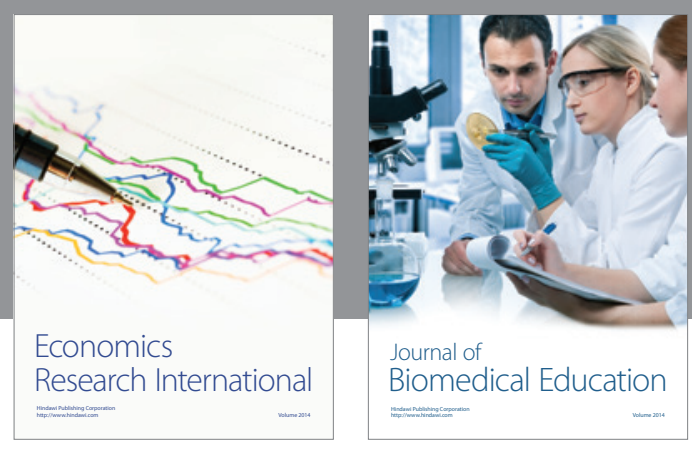

Journal of

Biomedical Education

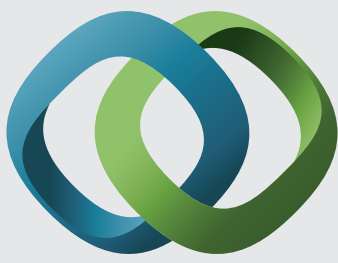

\section{Hindawi}

Submit your manuscripts at

http://www.hindawi.com
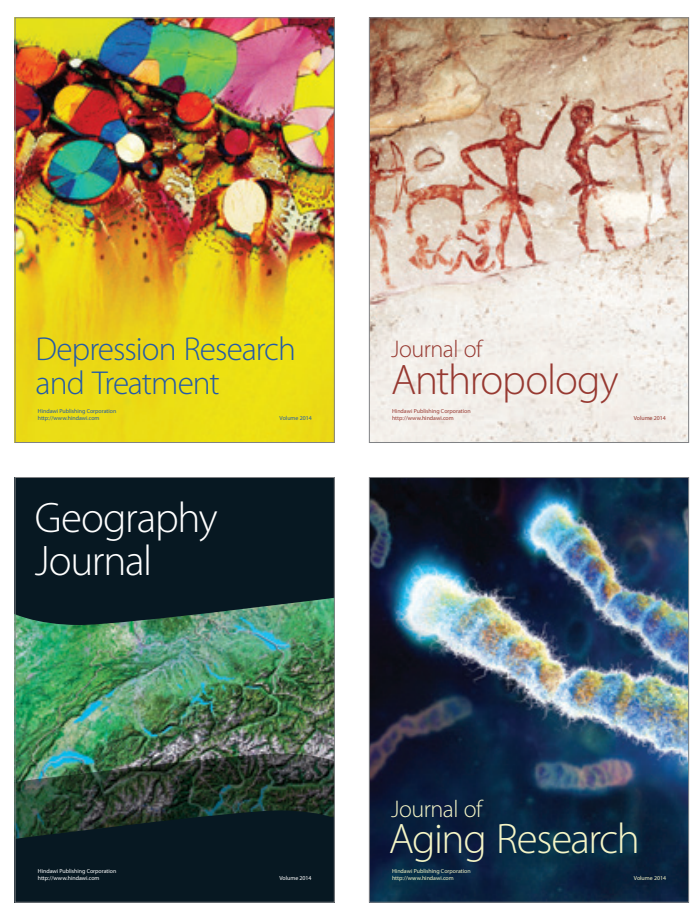

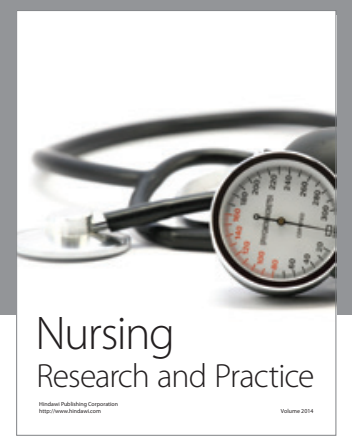

Nursing

Research and Practice

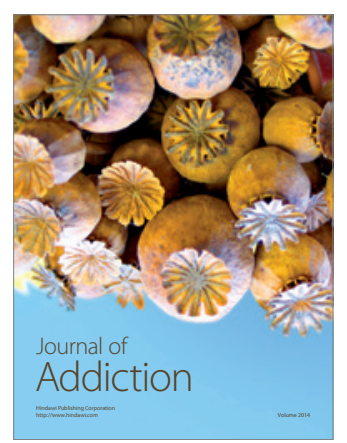

Child Development

Research

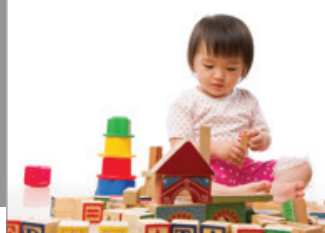

迥
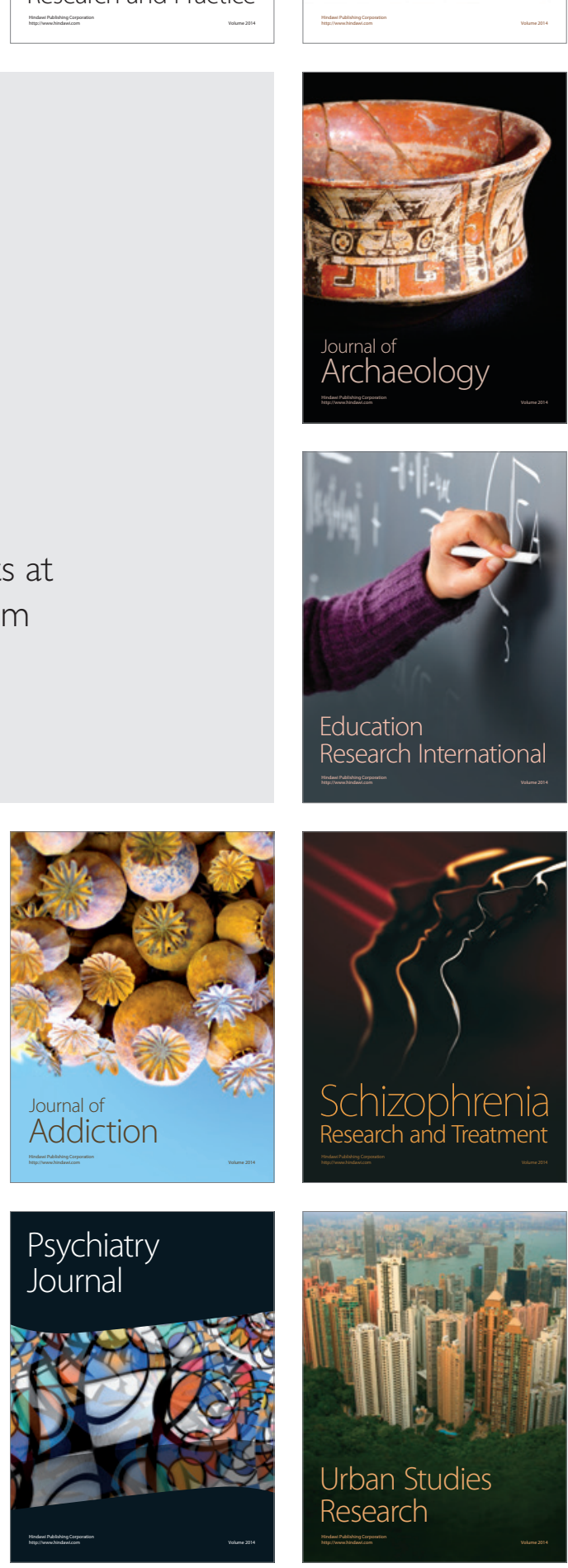